\title{
ACRL in San Francisco
}

\section{ACRL's programs at the ALA Annual Conference}

A LA's 120th Annual Conference was held June 14-20, 2001, in San Francisco. Total conference attendance was $18,961 \mathrm{mem}-$ bers, exhibitors, exhibits only, and guests, in cluding 19,694 paid registrants. Ed. note: Thanks to the ACRL members who summarized programs to make this report possible.

\section{The President's Program}

ACRL's President's Program "The Creative Genius of Community, "featuring Sherman Alexie, was the highlight of the conference.

Alexie-a Spokane Coeur D'Alene Native American; author of The Lone Ranger and Tonto Fist Fight in Heaven, Indian Killer, Reservation Blues, The Toughest Indian in the World; poet; and producer and screenwriter for the award-winning film Smoke Signals - delighted the audience by calling librarians "sex symbols."

Using stinging humor and the timing of the very best comedian, Alexie, the consummate storyteller, spoke of his life, stereotypes, and values. He described how the reservation library was a connection to a world outside of the "rez" for an unusual kid who was awkward, epileptic, studious, and wore glasses from age 2 .
Snowy River was the book that affected his life the mosc because there was a character in ic who looked like him. He talked about education as survival and how his planned medical education turned into creative writing. He talked about racism and how it victimizes. He spoke of how writers' works can transcend culture, touching others and propelling them to various actions.

He finished the pro gram by reading and later signing copies of the poem "The Summer of Black Widows," especially printed for the ACRL program. "The Elders knew the spiders carried stories in their stomachs. ..."

The poignant reading left the audience in awe of Alexie's creative genius and longing to hear more stories. It also left many grateful to be a part of a profession whose work helps to engender a creativity that brings so much to the larger community.-Memyll Penson, University System of Georgia, merryll_person@oit. peacbnet edu

\section{How to get published}

Four editors and two authors were panelists for the ACRL Research and Publications Committee's program "Getting Published and What it Takes: A Conversation with Editors 


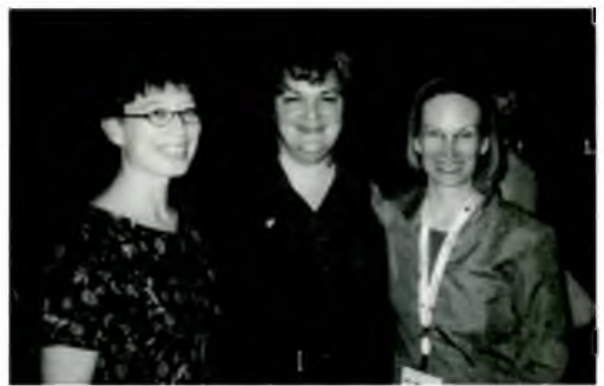

Lisa Hinchliffe (left) and Mary lane Petrowski (right) celebrate with I5 Miriam Dudley Instruction Librarian Award winner Patricia lannuzzi (center).

and Authors." Each panel member offered useful advice on issues such as writing style, research methodology, and the peer review process for prospective authors.

Mary Ellen Davis, outgoing editor-in-chief of CERL News, discussed editorial policy and enumerated numerous ways for authors to get started. She stated that CERL News is a magazine and sought to distinguish it from the other titles represented on the panel. CERL News is not refereed; Davis decides what is published and accepts 56 to 84 percent of the 70 to 90 articles a year that are submitted.

Hot topics, "How I Did it Good," and articles that address interesting solutions to common problems are the types of articles typically accepted. For those interested in getting started, she suggested writing eirher a library or non-library conference summary, sharing an idea for "News from the Field," writing an essay, or writing an Internet bibliography

Peter Hernon, editor of Journal of Aca demic Librarianship, stated that he copyedits every manuscript. Things such as the title, abstract, and first and last paragraphs will de termine the readership, and thus are very important. He identified satisfaction studies as the topic of greatest interest. He then discussed methods for data collection.

Donald Riggs, outgoing editor of College $\varepsilon$ Research Libraries, stated that the joumal has a 30 percent acceptance rate and has a double blind review. He is very interested in articles dealing with issues in the community college.

Gloriana St. Clair, editor of Portal, discussed the mentoring program the journal supports to reduce rejection rates.

The two authors, Julie M. Hurd (University of Illinois at Chicago) and Karen Schmidt (University of Illinois at Uibana-Champang), discussed the issues of formulating a topic, research methodology, and the writing and publication process-Mary Sellen, Unizersity at Albany, msells csc.albanyedu

\section{Unicode ${ }^{\mathrm{rM}}$ trends and applications}

At the Asjan, African and Middle Eastem Section program "Unicode: Representing the World's Languages Online: Trends and Applications, " panelists from OCLC, RLG, and VTLS discussed a wide gamut of issues relating to Unicode, and later participated in a lively Q\&A session.

Vinod Chachra (VTLS) began the session with an overview of Unicode and VTLS's native Unicode library system. Lynn Kellar (OCLC) discussed future plans for Unicode support at OCLC and urged users to contact her with suggestions (e-mail: kellarl@ocic.org). Walt Crawford (RLG) described RLG's current Unicode support in its catalog and indexing products. Following are links readers will find of interest.

From the Unicode( Consortium's Web site:

- What is Unicode? http:/www unicode. org/unicode/standard/WhatIsunicode.html

- The Unicode Standard: A Technical Introduction-http://www.unicode.org/ unicode/standard/principles.html

- Frequently Asked Questions-hip:// www unicode.org/unicode/faq/

Additional Web sites of interest are Joan Aliprand's two online presentations:

- "The Unicode Standard, Version 3.0: Content, Design Princoples, and Library Applications" - http://www uni-bamberg.de/unibib/ melcom/aliprand/index.htm

- "Unicode: Looking Ahead"-http:// www.lita.org/form98/aliprand/index htm (al- 
though Unicode 3.1 is now available, much of the information presented is still valid),

Finally, links from VTLS's and RLG's respectrve Web sites:

- http//www.vils.com/products/virtua/ subsystems/unicode/documents/tear_sheet pdf

- an article from RLG Focus on the addition of non-Rom.ın scripts to Eureka: http:// www.rlg.org/r-focus/147eureka.html.-Robin A. Paynter, University of Oregon, paynter@ oregon uoregonedu

\section{LES/ARTS beat as one in San Francisco}

Literature and art came together in perfect harmony during the program enticled "The Beat Generation: Collaboration and Community," which was presented jointly by the Lit eratures in English Section (IES) and ARTS sections. Original Beat writers Lawrence Ferlinghetti, Diane DiPrima, and Michael McClure were present and McClure began the program with a reading of his poem "For the Death of 100 Whales." He read several other selections and spoke briefly about his work.

Ann Charters, professor of English at the University of Connecticut and the author/editor of several books about the Beat movement, described the Beats' sense of commu nity and the way they "seemed to embody what they actually wrote." She read selections from letters written by Ferlinghetti during the 1960 s encouraging the Beat writers to keep working and indicating that the Beats were becoming more popular

Bill Morgan-painter bibliographer, and editor of Allen Ginsberg's work-argued that collaborations were not the best work of the Beats. His talk focused on examples of writers "collaborating with themselves," that is, using themes from their writing and exploring them in other media. "Pieces" by Burroughs, Ferlinghetti, Kerouac, Mcclure, Corso, and Ginsberg illustrated his thesis. Morgan summarized his talk with a quote from Jackson Pollock, "Every good artist paints what he is."

Paul Karlstrom, director of the West Coast Research Center, Archives of American Art, reminded the audience of the tremendous resources available in its collections, which represent the best of California art and culture, particularly visual art. Karlstrom interviewed many artists of the Beat scene, and the interviews are available in the collections. He commented on the incredible range and variecy of the artists' work: 'The work was about creating context." Another milestone of the era was the variery of different materials and media that emerged from the Beat ethos.

Janice Ross, professor in the Drama Department and the School of Education at

\section{Annual Conference audiocassettes available}

Audiocassettes of selected ACRL programs from the 2001 ALA Annual Conference in San Francisco are available. Each program consists of two cassettes for $\$ 28$, unless otherwise noted.

- Outside/In: Seeing Ourselves as Others See Us. Order no. AIA 112

- Virtual Space/Virtuous Place: College Lbraries in the 21 st Century, 3 cassettes, \$42. Order no. Al. 123

- Partners in Progress: Using Campus Partnerships to Promote Information Literacy. Order no. ALA 126.

- Old Friends, New Partners: Aca demic L.thraries Redefine $K-12$ Outreach, 1 cassette, $\$ 14$. Order no. AlA 128
- Getting published and What it Takes: A Conversation with Editors and Authors, 1 cassette, \$14. Order no. ALA 149

- Collecting the Twentieth Century, 3 cassettes, \$42. Order no. ALA 155

- Women Moving Mountains: Women and Organizations. Order no. ALA 134

Audiocassettes for other ALA programs are also available. Call in or fax your order to Teach 'em, 74-923 Hovley Lane East, Suite 250, Palm Desert, CA 92260; (800) 776-5454, fax: (760) 773-9671, credit cards only; c-mail: info@teachem,net; Web; www teachem.net/ ala. You may pay by check (payable to Teach 'em) or credit card (VISA, MC, AMEX). 
Stanford Universicy, spoke of dancer Anna Halprin and her connections with the Beats. Alchough she did collaborative works with a few of the authors, her strongest bond with the Beat community was aesthetic. Spontaneity, exploration, and the primacy of the group dynamic were similarly valued by Halprin and by the Beat artists and writers. Ross shared a rare video, "Hangar"- - a breathtaking, large scale improvisation by Halprin and her dancers at a San Francisco airport construction site.

The program concluded with some comments from Mcclure and a question-and-answer session. According to McClure, the Beats did what they did "not because we were hostile or angry, but because we were artists, "and that they considered themselves to be "desperados" against the dry character of sociely. When asked why the Beats' popularity extended beyond the 1950 s, McClure said it was because of their complete dedication and because so many of their interests are still important (e.g, protection of the environment).

Charters commented that the Beats have remained popular because "outsiders" tend to be celebrated and because their idealism set them apart.-Mantha Lawler, Louisiana State University at Sbreveport, mlawler@ pilot.Lus.edu, and Dena Thomas, University of New Mexico, drbomas@ummedu

\section{Media resources}

The ACRL Media Resources Committee program entitled "Media Resources 101: A Primer" delivered a delightful and practical continuing education exercise for media librarians both new and veteran to the profession.

The ACRL "Guidelines for Media Resources in Academic Libraries" (htcp://www.ala org/ acrl/guides/medresg html) came to life as a panel of seasoned medra librarians Randy Pitman (video librarian), Gary Handman (UCBerkeley), Kristine Brancolini (Indiana University), and Rick Provine (DePauw University) shared their personal experiences in planning, budgecing, and collection development

Pitman encouraged the audience to be involved in decision making for space and storage, to know your media, and to join professional organizations for continuing education and collegial support in a fluctuating field.

Handman stressed the need to make me dia collections accessible, including full cataloging and Web page listings, thereby promoting circulation. Having a collection development policy ensures a planned collection for long-term utility and an active collection responsive to user needs.

Brancolini pointed out that research supports the creation of a separate fund for purchasing media resources, and tying funding to circulation is a good way to draw attention to the demand and high usage of media resources. Resource sharing is another way to heighten the awareness of media, but you have to lend in order to borrow. Lending media resources among limited partners or within a local consortia is a good place to start.

Provine's remarks focused on facllity and space-planning needs. From personal experience he shares: You will need electricity and nerwork connections where you don't think you will; put in fat conduit and make it easy and cheap to pull wire; don't overbuy today's technology; never underestimate the power of furniture; plan for the growth of the collection; be advised that media is hazardous material, so pay attention to local fire codes; and don't for- 
get to allow for archival storage space in addition to space for the circulating collection.-Mary S. Konkel, University of Akron, marykonkel@uakron.edu

\section{Slavic collections in the Bay area}

The program of the Slavic and East European Section (SEES), "Slavic Collections in the San Francisco Bay Area and Their Impact on the Intellectual, Cultural, and Economic Life of the Local Community," highlighted the rich Slavic collections of many San Francisco Bay area libranes. These resources reflect the enormous Russian emigre population in the region, and the collections continue to grow and thrive in response to the needs of both the scholarly community and the local population.

Carol Leadenham, assistant archivist for reference at the Hoover Institution, discussed the enormous Russian collections at the Hoover Instiution library. Russian emigres donated many of the Russian collections after the Russian Revolution of 1917 and throughout the Cold War as they sought to protect their political, social, and cultural heritage from the Soviet regime. These donations were often given with the stipulation that they would be returned to Russia after the downfall of the Soviet Union, and now Hoover is working to film many of these papers in order to give a microfilm copy of these collections to Russian archives.

In recent years, the Hoover has also worked with the Museum of Russian Culture in San Francisco to microfilm its valuable and largely uncataloged collection of Russian emigre journals and newspapers.

Allan Urbanic, Slavic bibliographer at the University of California, Berkeley, spoke on the history of the Slavic collection at the university, which is one of the largest and oldest in the United States. Many of the most valuable items in the Slavic collection often find their way into the library when Russian êmigrês living in the local community donate them to preserve their heritage for future generations.

Other collections have been acquired because of political turmoil elsewhere; of particular note is the collection of manuscripts, speeches, books, and other papers of former Czechoslovak presidents Tomas Masaryk and Edward Benes. These materials miraculously survived the German occupation of Czechoslovakia and World War II and were secretly sent to Berkeley in 1946, just before the Soviet-controlled Czechoslovak government declared that all works by Masaryk and Benes be destroyed (for a more detailed account of the acquisition of this collection, see http:// www.lib.berkeley.edu/Collections/Slavic/ masaryk html).

Sharon Wilensky of the Richmond Branch of the San Francisco Public Library discussed the challenges of serving the newest wave of Russian immigration to the United States. The library strives to provide Russian-language books and newspapers for the local community despite low resources and high demand. Classics of Russian literature continue to be in high demand, with growing interest in the relatively new Russian romance and detective novel genres.

Also popular with the local community are computers in the library configured for use with Russian-language search engines and Russian movies on video. - Terri Tickle Miller, Micbigan State University, ticklet@msu.edu

\section{Women moving mountains}

Preceded by the presentation of two Women's Studies awards one for Significant Achievement to Marilyn Dunn and one for Career Achievement to Sarah Pritchard-the Women's Studies Section (WSS) program "Women Moving Mountains: Women and Organizations" raised significant issues regarding gender in the workplace. Speaker Kathryn Deiss (Chucago Library System) addressed issues for women in leadership and organizations

Starting with the status of women in librarianship, Deiss revealed Association of Research Libraries (ARL) statistics showing that the average salary of ARL directors is now equal between the sexes, but that women in other ARL positions only earn 93 percent of what men earn, i.e., "the pay gap still persists." As for employment in other occupations, women earn 76.5 percenc of what men earn even though women now comprise 50 percent of the workforce.

Deiss then discussed research results documented in the book Breaking the Glass Ceiling: Can Women Reach the Top of America's Largest Corporations? by Ann M. Morrison (Addison-Wesley, 1987). Findings revealed. 
that women must work harder than men to achieve the same recognition while playing multiple roles within society and the workplace. Success factors for women included receiving help from above (usually from males), non-threatening behavior, adapting to bosses with different styles, taking career risks, being tough, having a strong desire to succeed, and having an impressive appearance.

According to Desss, accivist women must: 1) make pay equity a reality, 2) supporr diverse workforces, and 3) study organizational cultures and then make changes. Her philosophy is that women do not have to pro. voke conflict to raise sticky issues as long as they treat people with respect.

Finally, Deiss stated that implementing rea] change involves moving away from strate gies of the past and developing new and innovative approaches-Mary $M$. Nofsinger, Wasbington State University Libraries, mnojsingousu.edu

\section{Redefining K-12 outreach}

Reaching out to potential university students was the focus of "Old Friends, New Partners: Academic Libraries Redefine $\mathrm{K}-12$ Outreach," sponsored by ACRL's Education and Behav-

\section{News from the University Libraries Section}

\section{Welcome to the 2001-02 academic year}

The University Libraries Section (ULS) had a banner year in 2000/2001 under the leadership of Elane Didier. John Seeley Brown, co-author of The Social Life of Information. headlined a terrific program at the conference. Additionally, ULS accomplished a long-time goal: establishment of a section newsletter entitled "ULS Universe."

Distributed via the ULS electronic list (another of the year's accomplishments), the newsletter provides communication from ULS to its 5,000-plus members and will inform and engage our membership in irnportant ways.

ULS members who haven't signed onto the electronic list are encouraged to do so. Important information about programs, discussion groups, committee opportunities, and other section information will be distributed regularly on the list. It's the best way to stay in touch and to communicate with other ULS members and leadership.

To sign on, send the following message to listproc@ala 1.ala.org. "subscribe uls-l first name last name.

During the coming year, you'll hear from our committee chairs about their plans for $2001 / 2002$. I an committed to listening to UIS members and involving as many of you as possible in the life of the section. If you have suggestions for the ULS Executive Committee or any of our committees or want to become more involved in the work of ULS, please contact me. I look forward to work- ing with you in the coming year-Julia Zimmerman, Obio University, julia. zimmerman@obio.edu

\section{Executive committee}

The ULS Executive Committee met twice during the ALA Annual Conference and continued to focus on activities furthering its strategic directions and the ACRL Strategic Plan. One of the key initiatives addressed by the Executive Committee is the work currently underway by ULS/CICLS/CLS to develop a combined publicity effort for acadernic Jibraries, including a Web tool kic for presenting certain library information in a common format.

The Executive Committee also reviewed several notable reports from ULS committees. Among these was the report of the ULS Standards and Guidelines Committee. Lori Goetsch (University of Maryland) reported on a proposal that would change the University Library Standards to a new model focusing on outcomes.

The proposal entails developing outcome measurements, establishing a clearinghouse for best practices, and asking ACRL to establish an office to assist with assessment and data interpretation. This approach is seen as being a better fit with the changing standards of accreditation agencies.

The 2002 Conference Program Planning Committee reported that Sheila Greth would be the lead speaker for the ULS program in Atlanta. The program, cosponsored with LAMA, is titled "Minding the Gap: Learn How 
ioral Sciences Section (EBSS). Panelist Gloria Rhodes, Mulcicultural Outreach librarian at Califomia State Unversity San Marcos, began by presenting some sobering figures about K-12 students in California seven of eight schools do not have a librarian half-time or more; the average number of library books per student in California schools is 11 ; the average imprint date for school library books is 1972 .

Rhodes then explained the importance of positive and instructive library experiences for California school children. She described her program for fourth graders called "I Am
Going to College, ${ }^{n}$ in which children learn that college is a viable option. The intimidating impression of libraries and librarians is eliminated. On a practical level, the students are motivated to become excited about successfully completing a research project. Rhodes urged all academic librarians to be proactive in this type of endeavor.

Sandra Millard, assistant director for Library Public Services and program director, UDLib/ SEARCH at the University of Delaware, enthusiastically described the parnership between the University of Delaware and the State of Delaware, which provides all state public

\section{(continued from previous page)}

to Communicate and Work Together Across Generations."

Academic libraries, like other organizations, face challenges posed by generational differences in their workforces. The program will focus on work style differences, management issues, and working collaboratively across generations

\section{Heads of Public Services}

The ULS Public Service Directors of Large Research Libraries Discussion Group, convened by Lucinda Covert-Vail (New York University), enjoyed a lively conversation about cybercafes and food in the library.

Janice Koyama described UCLA's highly successtul approach to marketing an approved beverage container for use in the libraries. The handsome plastic mug is emblazoned with the phrase, "Drink. Think." Its leak-proof capability was demonstrated by holding a mug full of water upside down over the meeting room carpet.

There were also discussions of the lively cafes adjoining the libraries at Michigan State and UC Berkeley. Berkeley's Free Speech Movement Cafe at the Moffitt Library was reported to be crowded all the time-even placing an unexpected strain on restroom facilities. Library cafes appear to be extremely popular with campus communities.

The second major discussion topic for the group was library signage. Covert-Vail explained NYU's limitations on cell phone use in the library and how it was implemented through signage. Gordon Aamon presented the University of Washington Librarses' comprehensive signage policies and guidelines. Ann Thornton discussed the signage problems of NYPL's Science, Industry and Business Library. She noted how the initially minimalist signage program for the facility soon gave way to a proliferation of informal signs. She described the library's approach to minimizing intrusive signs yet still communicating certain essential messages.

Mary Jackson provided the public services directors with an update from Association of Research Libraries (ARL) and announced the November IL.L/DD conference in Ann Arbor. She also described the Scholar's Portal Project and its current status. The project seeks to provide a Web search engine that searches locally licensed and high-qualicy, publicly accessible electronic resources. Search results would appear in a single, integrated presentation.

The group's meeting ended with a discussion of its membership. Several proposals to expand the discussion group were considered, using ARI membership or Carnegie Doctoral/Research University Extensive classification, as the criterion. The discussion will be continued at the Midwinter Meeting with Diane Strauss (University of North Carolina at Chapel Hill) as the new convenor.-John Lebner, Universily of Hous ton, jlebner@ub.edu 
middle and high schools access to online encyclopedias and fulltext magazine/journal dacabases.

Critical to the success of this program is the training, conducted by college librarians, of school librarians and teachers. Millard stressed that the support of the stace legislacure and administration is critical to the program's growing success.

Stephanje SterlingBrasley, Instructional Outreach coordinator at UCLA, described the problems and time needed to set up a successful program between the university, high schools, and com-

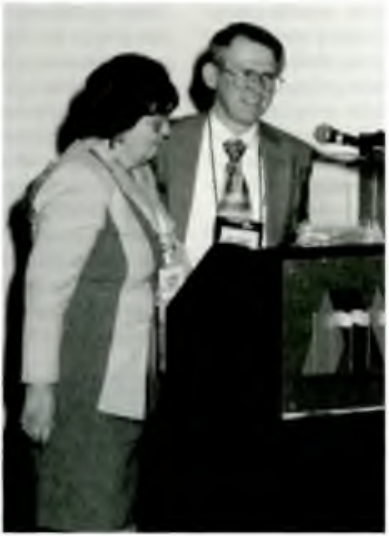

Carol Hardesty congratulates Academid Research Librarian of the Year, Larry Hardesty. munity colleges. The premise under which they operated was that "college begins in kindergarten"

A pilot project indicated the critical factor of training teachers to incorporate technology into the curriculum. Most important for the success of the program was for librarians to assist teachers in improving their information literacy skills, which could then be taught to students. $-N a n c y$ Koller; University of California, Riverside, nancy.kollen@ucredu

\section{Partners in progress}

The Instruction Section (IS) presented "Partners in Progress: Using Campus Partnerships to Promote Infomation Literacy"

Larry Hardesty, library director at Austin College, kicked off the panel discussion by examining faculty members' attiudes towards the library. Hardesty said faculty see librarians in a concinuum from the guardians of a large study hall to full partners in teaching undergraduates.

"There is considerable evidence that classroom faculty at most institutions do not actively involve the library in their teaching," he concluded. Hardesty recommended personal contact as the key to recruiting faculty partners.
Sally Murphy, professor of Communication Studies and General Education coordinator at California State University (CSU) at Hayward, provided a perspective from outside the library.

Murphy described how librarians at her institution succeeded in making an information literacy course a general education requirement. Because librarians are faculty members at CSU, they were involved in the university course development process from the start Murphy pointed out that being thoroughly prepared helped the librarians make their case.

"They had articulated learning outcomes before anybody else had articulated learning outcomes on campus," she said. After the course was institured, the librarians used assessment tools to prove its effectiveness

Patricia Ianuzzi, associate university librarian and director of Doe/Moffitt Libraries at the University of Californa ar Berkley, discussed the strategies and politics of finding collaborative partners. She suggested identifying the hot topics on campus, and then showing how information literacy can help make campus initiatives succeed.

"The future of academic librarianship hinges upon our ability to step up and into our roles as partners in the educational process on campus," Ianuzzi said-Patrick Oberboltzer, Gallaidet University, patrick. oberboltzer@gallandetedu

\section{Models for distance learning services}

The Distance Learning Secaon (DLS) presented "Integrare, Separate, or Outsource? Models for Distance Learning Services." Alexander (Sandy) Slade, coauthor of Library Services for Open and Distance Leaming. began the program with an excellent overview of current trends, issues, and hot topics in distance learning library services. 
Steve Schafer, director of library services at Athabasca University, discussed the integrated services model and his library's extensive experience with providing distance services with the same units that provide inhouse services. The library is also well integrated with the university's budgeting, planning, and evaluation processes.

Anne Marie Casey, director of Off-Campus Library Services (OCLS) at Central Michigan University (CMU), presented the separated model, where distance services are staffed and often funded separately from inhouse library service units/staff OCLS provides full library services exclusively to CMU's College of Extended Learning (CEL) students and faculty. While the library services receive tremendous support from CEL, "We are neither fish nor fowl," Casey explained as she listed the pros and cons of being functionally and fiscally integrated with CEL, while reporting to the dean of the CMU library system.

The outsourcing model was discussed by Kim Dority, vice president of E-Global Library (EGL). Dority outlined the types of services libraries or commercial service providers should be offering to distance learners, using specific examples of EGL services to illustrate her points.

"We are not doing anything that you could not be doing yourself," she told the audience, but asked us to consider how we should be using our limited resources when deciding whether and when to outsource distance library services.

"For many years distance library services have been marginalized, but now they are getting recognition and attention," commented Slade in his conclusion to the program. His outline of future trends and a list of issues specifically for library administrators sent the audience off with a great deal to ponderSusan M. Davis, Gallaudet University, susan.davis@gallundet.edu

\section{Academic libraries in the 21st century}

Ever wonder what role the traditional library has as a center of culture and learning in an emerging virtual environment? Or, worry about defining your institution's ongoing need for a physical library to a college administration, which sees the virtual library as its replacement? These issues and more were ad- dressed by the College Library Section's (CLS) program "Virtual Space/Virtuous Place: Academic Libraries in the 21st Century."

LaVerna Saunders, acting vice president for Academic Affairs at Salem State College, stressed the importance of being an active listener to patrons' needs, urging librarians to be political in getting outside of the library building and having a presence in the virtual world. Being creative in finding ways to communicate that the virtual library is now part of the academic culture and needs to be used to provide access to information services is key.

Stephanie Bangert, assistant director of the Western Association of Schools and Colleges, noted that "learning is at the heart of human interaction," and patrons of the 21 st century will be active learners, taking responsibility for their own learning experiences and outcomes. Librarians should understand how the learning requirements of the institution are defined, in terms of the students' abilities to multitask, adapt, and self-regulate. She encouraged the audience to understand how the learning experience aligns with institutional purpose.

Sam Demas, college librarian at Carleton College, spoke of creating opportunities for developing imaginative spaces for learning in the library, seeing the library as an agent in community building and as a cultural center that can enliven campus social life in celebration of community interests.

Joyce Ray, director of Institute of Museum and Library Services, described the IMLS's inperative to foster leadership, innovation, and lifetime learning by the support of museums and libraries. IMLS encourages innovative partnerships and projects to improve access and services to libraries and their collections.

Deanna B. Marcum, president of the Council on Library and Information Resources, spoke of the history of libraries as the place of record, as evidentiary collections, as intellectual centers - as virtuous places. She challenged the audience to think about a metaphor for the virtual library, one which encompasses library virtues, but also reconceptualizes our efforts in a digital world.-Renee Jadushlever, Mills College, reneejad@mills.edu 


\section{Social movements, marginalized groups, and the Internet}

The Anthropology and Sociology Section (ANSS) program, "Social Movements, Marginalized Groups, and the Intemet: Issues for Librarians and Researchers," consisted of four speakers who described various uses of the Internet to increase the visibility and $1 \mathrm{~m}$ pact of social movements and marginalized groups.

Harry Cleaver, Economics professor at the University of 'Texas at Austin, examined the new electronic environment developed by advocacy organizations to publicize their activities and disseminate news and research. "For social activists," Cleaver stated, "the Internet has both broadened and facilitated their research to frame and understand the array of activities, policy, and institutions against which they struggle. . . [And], the extremely low cost of electronic information storage and retrieval has made it possible for activists to create their own electronic libraries of information."

He urged university libraries to collect, archive and preserve the documents, electronic list discussions, and Web sites of these movements in order to offer unprecedented access to perspectives and mobilization from the bottom up

Marc Becker, History professor at Truman State University, founded NativeWeb (www. nativeweb.org) to extend technology resources to indigenous peoples around the world and to serve as a repository for their original documents and research. Becker described the possibilities and pitfalls of bringing modern technology to the most marginalized areas in the world.

Mark Graham, vice president of Technology for ivillage and chair of the advisory board of the Institute for Global Communications, spoke about the involvement of progressive social movements in reshaping world politics. He cited the following trend toward uniformiry and centralization on the Web as a clear indication that diversity needs to be nurtured on the Internet "Net surfers spend about 60 percent of their time online using products and services owned by just 14 companies, down from 110 companies merely two years ago."

He commended libraries that have developed ways to increase the diversity of their resources by using the Internet. Graham re- ferred to several Web projects that offer access to and archiving of information not typically included in the mainstream media (sites mentioned by Graham are listed at http:// www.well.com/user/mgraham/plists.htmD).

Itibari Zulu, director of the UCJA Center for African American Studies Library, described several projects that promote needed examination of the relationship between information resources (or lack thereof) and social justice issues.-Rhonda L. Nengeboner; University of Calyomia, Riverside, rbonda. neugebauenoucredu

\section{Including the voices of Spain's excluded communities}

The Western European Studies Section (WESS) examined Spain in "Exploding Spanish Canons: Including the Voices of Spain's Excluded Communities."

Ramon Abad (Cervantes Institute, New York) launched the program with "Rescued from Oblivion: Emigration and Inmigration in Contemporary Spain through Literature and Cinema." He raised a broad range of immigration issues currently hot in the Spanish media. His message: it is still too early for recent immigrants to have their own voice

Silvia Bermudez (University of California, Santa Barbara) presented "Playing the Field," a feminist interpretation of literature's role as cultural capital. She focused on the modern Galician state, stressing the significance of the journal Festa da Palabra as a forum for fem1nist literature and scholarship. Even though Spanish society has undergone dramatic social changes recently, Bermudez bemoans the continued "tokenism" of women artists in its cultural organizations.

David William Foster (Arizona State University) concluded with "Lesbigay Publishing in Spain." Even with the opening of Spanish society over the past two decades, translations of American and other authors provide the bulk of Spanish lesbigay publishing. Foster described the small reading public of Spain, the distinct gender gap in production of lesbigay writings, and the distribution of queer theory publications.

Foster ended with "Queer Iberia," a concept whose origins lie in the richness of Spanish cultural, religious, and ethnic diversity, in teracting and resisting traditional patriarchal organizations and structures. 


\section{EBSCO can help you find the solution...}

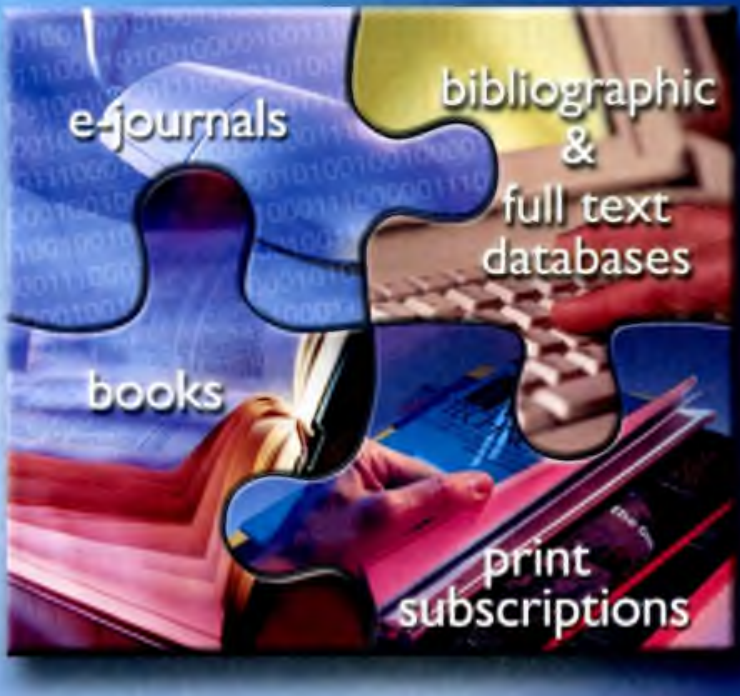

\section{for bringing together the pieces of your information collection.}

For more than 50 years EBSCO has provided subscription management services to libraries and organizations of all types. Today, we offer solutions for many of your library's information resources - e-journals, databases, print subscriptions and books - backed by the same superior service for which we have always been known
For more information, visit us online at www.ebsco.com

Our integrated online research services give users easy access to full text in databases and electronic journals. EBSCO Book Services allows administrators to manage indlvidual book purchases from their desktops. And virtually all aspects of serial subscriptions can be managed efficiently through our EBSCONET' Serials Management System. All services are offered through and supported by EBSCO's Regional Office network, covering 21 countries and $\mathrm{six}$ continents.

EBSCO Information Services... bringing together the pieces of your information collection.

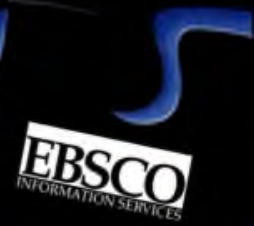

